University of Nebraska - Lincoln

DigitalCommons@University of Nebraska - Lincoln

Faculty Publications from the Harold W. Manter Laboratory of Parasitology

2002

\title{
Foundations for an Integrative Parasitology: Collections, Archives, and Biodiversity Informatics
}

\author{
Eric P. Hoberg \\ United States Department of Agriculture, Agricultural Research Service, geocolonizer@gmail.com
}

Follow this and additional works at: https://digitalcommons.unl.edu/parasitologyfacpubs

Part of the Biodiversity Commons, Bioinformatics Commons, and the Parasitology Commons

Hoberg, Eric P., "Foundations for an Integrative Parasitology: Collections, Archives, and Biodiversity Informatics" (2002). Faculty Publications from the Harold W. Manter Laboratory of Parasitology. 662. https://digitalcommons.unl.edu/parasitologyfacpubs/662

This Article is brought to you for free and open access by the Parasitology, Harold W. Manter Laboratory of at DigitalCommons@University of Nebraska - Lincoln. It has been accepted for inclusion in Faculty Publications from the Harold W. Manter Laboratory of Parasitology by an authorized administrator of DigitalCommons@University of Nebraska - Lincoln. 
Comp. Parasitol.

69(2), 2002, pp. 124-131

\title{
President's Symposium
}

\section{Foundations for an Integrative Parasitology: Collections, Archives, and Biodiversity Informatics}

\author{
ERIC P. HOBERG \\ U.S. National Parasite Collection and Parasite Biology, Epidemiology and Systematics Laboratory, \\ Agricultural Research Service, U.S. Department of Agriculture, BARC East No. 1180, 10300 Baltimore \\ Avenue, Beltsville, Maryland 20715, U.S.A. (email: ehoberg@anri.barc.usda.gov)
}

Burgeoning awareness about biodiversity emphasizes the fundamental importance of museum collections and the contributions of systematists and taxonomists in documenting the structure and history of the biosphere. An essential role is served by this infrastructure in collecting, preparing, analyzing, and disseminating information about the specimens that represent species, document a range of complex biological associations from symbioses to parasitism, and form the tapestry and the myriad facets of biodiversity (e.g., Wilson, 2000). As parasitologists we can examine how we may contribute to this broader documentation and understanding of global biodiversity, and we can articulate and communicate our role as vital participants to a larger community (e.g., Brooks and Hoberg, 2000, 2001). This becomes increasingly important as we continue to recognize that the effects of parasites on humans, domestic animal food resources, and wild biodiversity are a major international concern in this time of dynamic environmental change. At the international level parasites are now viewed as significant components of biodiversity that must be included in plans for survey and inventory, conservation, and other national needs focused on understanding environmental integrity and ecosystem function (e.g., Just, 1998; Pérez-Ponce de León and Garcia-Prieto, 2001a, b, and references therein).

Although a core number of museum and institutional collections have been vital for the development of parasitology in North America, in the broader museum community there has been a relatively limited presence of systematists and taxonomists focusing on parasitic taxa. Additionally, in North America there has not been a longstanding tradition for support and development of museum collections, resources, and curatorial positions for parasitology on the scale evident for programs focusing on many free-liv- ing invertebrate and vertebrate groups. This is not a lament, but simply history. Parasitology has generally not been a factor in the development or programs of most major natural history museums, and the discipline tended to develop along a divergent track, to become dominated by private or personal collections. Over time, and particularly in the last $25 \mathrm{yr}$, this dispersed infrastructure has contributed to an incremental erosion by attrition of our systematics knowledge and expertise. Further, the tradition of often closely held, large personal collections has limited the communication, progress, and growth of a cohesive systematics community and has now exacerbated the challenge to provide curatorial services and databasing for an increasing number of significant orphan collections. Only 4 major repositories or specimens-based collections of zooparasites now exist in North America, 3 serving endoparasites, and 1 focusing on arthropod ectoparasites (Lichtenfels, 1994), and a critical mass for research infrastructure diminishes annually.

We can recognize that parasitology has made seminal contributions to our understanding of the structure and history of the biosphere (summarized in part in Brooks and McLennan, 1993; Hoberg, 1997a). Parasitologists can choose to build on the nexus between biodiversity studies and parasitology and concurrently construct a necessary infrastructure that enhances the impact of museum collections and affords the expansion of opportunities for future generations of systematists and taxonomists. Of course, this is not the only future for parasitology, but 1 significant cornerstone that emphasizes our classical contributions while building a modern and cutting edge tool kit for exploration and discovery. Parasitology must reaffirm its commitment to systematics; otherwise, the future of parasite systematics will be decided by nonparasitolo- 
gists. In this context, comments herein will be focused on several areas: 1) resources and infrastructure for museum collections, with particular focus on the history and dual roles and responsibilities of the Agricultural Research Service (ARS) and the U.S. National Parasite Collection (USNPC); 2) biodiversity and systematics as essential foundations for research in parasitology (e.g., Brooks and Hoberg, 2000); 3) the evolution of collections from static repositories to functional information systems in the realm of biodiversity bioinformatics (e.g., Blackmore, 1996; Bisby, 2000; Edwards et al., 2000); and 4) examination of the challenges and opportunities facing parasitology in responding to the needs of science and society.

\section{THE USNPC: A CENTURY OF SERVICE}

The ARS of the U.S. Department of Agriculture (USDA) has been the home for missionoriented and problem-solving research on parasites and pathogens that directly or indirectly threaten animal health, food safety, and the environment. A core facility within the current laboratory structure is the USNPC located at the Henry A. Wallace Beltsville Agricultural Research Center near Washington, D.C.

Since 1892 the parasitological collections held by the USDA have been the focus for development of knowledge about the distribution of parasites, pathogens, and diseases (Lichtenfels et al., 1992, 1998). The evolution of these collections has followed the expansion of research programs targeted to solve a number of emerging problems for agriculture during the last century. Concurrently, what is now the USNPC became the focal point for field-based and empirical research emphasizing survey and inventory, systematics, biogeography, and ecology among a diverse assemblage of helminth and protozoan parasites of vertebrates and contributed to experimental studies to address the biology of an array of economically significant parasites. Thus, over the past century, the USNPC has served an essential and dual role for science and society in both providing a foundation of knowledge about the host and geographic distribution of parasites and contributing to the resolution of a number of real world problems facing farm and industrial production of food animals, food safety, and protection of the environment.

The USNPC, a national and international re- source for systematic, taxonomic, and diagnostic ecological and epidemiological research in parasitology has been continuously maintained by the USDA for over $100 \mathrm{yr}$ (Lichtenfels et al., 1992; Lichtenfels, 1994; Lichtenfels et al., 1998). The USNPC has served as a critical resource for all aspects of parasitology in North America and globally and provides the foundation for all programs within the ARS and elsewhere that deal with the systematics and taxonomy of agriculturally and economically significant helminthic and protozoan parasites. The scope and depth of the Collection are unparalleled in North America. The current holdings are substantial, and the collection is among the largest in the world (in excess of 100,000 lots, and over 20 million individual specimens; 3,000 holotypes, 7,000 type series) and accumulates about 1,000-1,500 new lots of specimens annually. A primary role of the USNPC is acquisition, curation, and long-term maintenance of the specimens-based collections, and development and expansion of the collections database as an irreplaceable national archive. The specimen collection is linked to extensive documentation of host occurrence, geographic range, and other core data with which to assess the current and historical distribution of parasites and pathogens, with a database accessed through the Internet (http://www.anri.barc.usda.gov/pbesl).

A uniquely federal role is served by the Collection as a center for diagnostics, identification, and dissemination of information. Parasitologists in the ARS and others working in veterinary, medical, and wildlife parasitology have access to the necessary specimens and database to conduct studies on the identification, classification, and distribution of parasitic helminths and protozoans. The specimens collections, accumulated over $150 \mathrm{yr}$, are a historical baseline and resource for biodiversity research globally. The collection is the foundation for proactive programs, prediction, and prevention with respect to parasites and pathogens that pose risks to the health of animals, humans, and the environment. The USNPC's vision focuses on these issues: "Serving society through biodiversity discovery and exploration, systematics, predictive classifications, and interactive information systems for parasites that contribute to identification of new and emerging threats to animal health, food safety, and the environment."

The USNPC serves a diverse and global con- 
stituency, providing curation and access to specimens and databases that drive parasitological research. The combined resources of the USNPC and its substantial sister-collections, including the Harold W. Manter Laboratory (University of Nebraska State Museum), the U.S. National Tick Collection (Georgia Southern University), the Canadian Museum of Nature, and other smaller taxonomically focused institutional facilities (Lichtenfels, 1994), form the primary infrastructure for systematics, taxonomy, and biodiversity of metazoan and protozoan parasites in North America. In the current environment we have an opportunity to formulate policy and seek synergistic interfaces within this community of systematics collections to further a broad goal of contributing to a comprehensive knowledge of parasite biodiversity at local, regional, and global scales.

\section{COLLECTIONS AS INFORMATION SYSTEMS}

The current view of the USNPC and other collections is that to remain vital and relevant, we must be in a position to develop our resources as information systems. It is not enough to simply hold and maintain specimens in a static repository; in this sense size doesn't matter; rather, it is the information contained in unique specimens as a representation of a complex biosphere that is significant. We have an obligation to maximize the information content of collections and to disseminate this information to a broad-based user community (e.g., Blackmore, 1996). Such an approach is consistent with the current mandate of the Convention on Biological Diversity (CBD) and the Global Taxonomy Initiative (GTI), which seek to improve taxonomic knowledge and the capacity to meet a country's needs and support activities for conservation, sustainable use, and equitable sharing of benefits and knowledge of biodiversity (Creswell, 2000).

Components of a parasitological information system should include specimens-based biodiversity inventories, comprehensive species lists, validation of morphological information, summaries of key phylogenetically diagnostic characters, and total evidence systems incorporating morphological, molecular, and genomic data. Development of integrated information systems linking parasite, host, and geographic (geo-referenced) data and development of applications for geographic information systems (GIS) is another goal. In this context, specimen-based data can serve as historical or temporal baselines and archives for understanding the influence of environmental change or human intervention on the distribution of parasites and pathogens. Interactive information systems linking diagnostic keys with phylogenetic and epidemiological and biological information for access on the World Wide Web are also central to this concept. In essence the logical course for growth and relevancy of parasite collections is in building the infrastructure for biodiversity bioinformatics, with museum staff serving as "curators of information," where a series of interrelated data frameworks within and among museums collectively summarize our base of knowledge in a synergistic manner (Bisby, 2000; Brooks and Hoberg, 2000, 2001).

Biodiversity informatics represents an essential contribution through formulation of relational databases and development of interactive information systems that represent the next step in managing and disseminating parasitological data derived from specimens-based collections. At a general level, we can formulate and contribute to a new paradigm of parasite collections as information systems by building a world of distributed databases linking specimens-based collections. Parasites thus become a window on the world revealing facets of biocomplexity, and further, become resources for documenting biodiversity as a general reference system for the dynamics of intricate biological associations.

\section{THE CHALLENGE FOR PARASITE SYSTEMATICS}

Systematists are purveyors of basic information about species, and it is the systematics community that collectively creates the foundations for biodiversity informatics. Systematists hold and codify their special knowledge in the form of species names that represent the physical and ecological characteristics of known organisms, which are the essential elements of genealogical reference systems. Systematics is also the framework for comparative studies in basic and applied biology. In parasitology, systematics research is the predictive foundation for recognizing emergent and invasive species, documenting patterns of distribution for pathogens and disease, applied epidemiology, and successful intervention either through management or through the use of therapeutic approaches. Further, accurate morphological characterization of 
parasites and phylogenetic frameworks are critical for the reliability of any capabilities for molecular diagnostics and comparative genomics. In a broader context, parasites are critically important as 1) ecological and trophic indicators; 2) historical indicators of phylogeny, ecology, and biogeography; 3) contemporary and historical probes for biodiversity research; and 4) model systems for exploring a range of theoretical issues in evolutionary biology, and ecosystem and community structure using a comparative approach (Brooks and Hoberg, 2000). Simply, in the absence of systematics, parasitology, and biological science in general, could not proceed.

Although the need for expanding knowledge and the inventory of global biodiversity is widely recognized, our abilities to realize this goal are hampered by the "taxonomic impediment" - basically a worldwide shortage of critical expertise in systematics (SA 2000, 1994; Hoagland, 1996; Brooks and Hoberg, 2000). For example, it has been noted that within the USDA inadequate support of taxonomic and systematics expertise has had an adverse impact on mission-oriented research linked to biodiversity (PCAST, 1998). Capabilities for parasite systematics are not broadly represented among other federal agencies where such would be appropriate, and they do not represent core programs except at a few academic institutions in North America.

Comparative studies using phylogenetic information have rapidly expanded in the past decade. A growing number of applied research programs in parasitology have recognized this and are using phylogenetic information in their studies. Although the taxonomic impediment remains apparent, there has been attention to development of phylogenies for groups that include important helminth parasites of humans and livestock (e.g., for ascaridoid nematodes, Nadler and Hudspeth, 2000; trichostrongyloid nematodes, Hoberg and Lichtenfels, 1994; Gouÿ de Bellocq et al., 2001; taeniid tapeworms, Hoberg, Alkire, et al., 2001), and phylogenetic approaches have figured prominently in recent studies of the Apicomplexa (e.g., Barta, 1989; Carreno et al., 1998).

Despite the challenges of the current environment, systematic parasitology has made substantial contributions in resolving the evolutionary relationships among the major parasitic groups, particularly among the Platyhelminthes (e.g., Brooks et al., 1985; Brooks and McLennan, 1993; Littlewood and Bray, 2001). Indeed, there has been a largely unrecognized revolution in parasite systematics, beginning only $25 \mathrm{yr}$ ago with the publication of the first phylogenetic study of any group of parasites by D. R. Brooks (1977), that has resulted in a deep phylogenetic understanding within some taxa. For example, a cumulative and hierarchical base of knowledge about tapeworm phylogeny has blossomed in the $5 \mathrm{yr}$ since the 2nd International Workshop for Tapeworm Systematics (Hoberg, Gardner, et al., 1997), which resulted in 1999 in a series of papers in Systematic Parasitology, Vol. 42. The Workshop and these studies served as a foundation for the development and evaluation of a series of testable hypotheses for higher level relationships (Hoberg, Mariaux, et al., 1997; Justine, 1998; Mariaux, 1998; Caira et al., 1999; Olson and Caira, 1999; Caira et al., 2001) that have culminated in recent attempts to integrate molecular and morphological databases and analyses based on total evidence (e.g., Hoberg, Mariaux, et al., 2001; Olson et al., 2001). Through these studies, many of which have extended to the level of resolution among families, genera, and species, the tapeworms must now be considered among the best resolved of any group of organisms, free-living or parasitic.

Surprisingly, this basic information on the genealogical diversity of the tapeworms and parallel data for other parasitic flatworms, based on both morphological and molecular databases, are not yet widely represented in the Tree of Life (TOL) (Morell, 1996; Pennisi, 2001). Inclusion in the TOL should offer parasite systematists a diverse audience for our contributions toward understanding the history of life, the universe, and everything. Parasitologists must take the opportunity to fully engage the broader community and communicate the depth and scope of the phylogenetically driven research programs that emanate from the discipline. Collectively, as we move toward a clearer resolution of relationships for a diversity of parasitic taxa, we can begin to articulate and evaluate fundamental questions about the structure and history of the biosphere (Brooks and McLennan, 1993; Hoberg, 1997a). Notably, we enter the twenty-first century with a robust phylogenetic hypothesis, at a minimum to the family level, for all of the Neodermata, and have begun to accumulate the molecular 
data necessary to explore a rich and detailed history for these taxa (see Littlewood and Bray, 2001). (For a listing of most published phylogenetic trees for parasitic helminths, see http:// brooksweb.zoo.utoronto.ca/notes.html.)

\section{BIODIVERSITY AS A FOUNDATION}

There is nothing more fundamental than a comprehensive understanding of parasite biodiversity, including accurate taxonomy and species identity, evolutionary relationships, geographic distribution, and host associations (Brooks and Hoberg, 2000). Parasites satisfy the primary criteria for recognition of priority taxa to be included in survey and inventory within the GTI (Brooks and Hoberg, 2001). These criteria include 1) taxa that are intrinsically important to humans; 2) taxa that are intrinsically important to ecosystems that humans want to preserve; 3) taxa that provide efficient means of learning something of importance; 4) taxa that are geographically widespread; and 5) taxa that provide an opportunity for international networking. Parasites are admirably suited for inclusion in basic survey and inventory of other vertebrate and invertebrate taxa and collectively provide substantially greater information than that derived from the study of free-living organisms alone, while causing substantial socioeconomic impacts on a global scale (Hoberg, 1997a, b).

Incomplete documentation of the biodiversity of the global parasite fauna, from the level of species to populations, continues to hamper the development of relevant control measures, and parasites continue to affect science and society significantly. Accurate survey and inventory is critical for recognizing the potential emergence of pathogens, and interactions between the parasite faunas circulating in domestic and sylvatic hosts and at the interface of agricultural or managed and wild ecosystems (Hoberg, 1997b; Hoberg et al., 1999; Brooks and Hoberg, 2000). Globalization of economies indicates that narrow regional approaches to documentation of diversity for parasites and pathogens are no longer supportable or viable. Translocation and introduction of parasites continue as factors determining the continental and global distribution of pathogens and further emphasize the importance of systematics and taxonomy in providing a predictive framework for identification, documentation, and subsequent surveillance and moni- toring (Hoberg, 1997b; Hoberg, Kocan, et al., 2001; Pérez-Ponce de León et al., 2000). These issues again emphasize the importance of collections that serve as the foundations for inventories of the world's biota (Blackmore, 1996) and reinforce the significance of the development of our specimens-based resources as primary information systems for biodiversity.

At a more fundamental level parasites are the integrative core of biodiversity survey and inventory (Hoberg, 1997a). Parasites yield insights into the origins and continuity of biota and the historical, phylogenetic, ecological, biogeographic, and temporal connectivity across and within ecosystems (the linkage of macro- and microevolutionary processes, and temporal and geographic scale). Parasites are critical in developing a synoptic understanding of the history and structure of the biosphere. Substantial contributions by parasitological research to biodiversity inventories extend from the accretion of novel information from the standard surveys established over the past $200 \mathrm{yr}$ to sophisticated research programs for systematics, ecology, biogeography, and evolutionary biology, based on both organismal and molecular approaches (Brooks and Hoberg, 2000). For example, see the database for the inventory of all eukaryotic $p$ arasites of 940 species of vertebrates living in the Area de Conservacion Guanacaste, Costa Rica (http://brooksweb.zoo.utoronto.ca/notes. html), and the developing databases for the Beringian Coevolution Project being assembled to examine the complex history of the northern continents (http://arctos.museum.uaf.edu:8080/ projects/0051/index.shtml).

\section{CHALLENGE FOR THE FUTURE: PARASITE SYSTEMATICS AND COLLECTIONS IN A CHANGING WORLD}

Systematics and our specimens-based collections are the foundation of all that has been accomplished in parasitology and have resolved a substantial number of real-world problems in human and animal health. Comparative phylogenetic approaches, in their infancy only $20 \mathrm{yr}$ ago, have now become the standard (Brooks and Hoberg, 2000). Yet, with this impressive array of contributions and tools, and growing interest in parasitology at all levels of society (e.g., Zimmer, 2000), our future does not seem assured.

The parasitology community, often at the institutional level, has undervalued museum col- 
lections, although collections are increasingly important in the context of burgeoning programs for biodiversity survey and inventory and hold irreplaceable baseline and archival knowledge of the biosphere. It appears to be a general assumption that these resources will simply continue to exist and provide essential services in the absence of any community-level support or support from the stakeholders who are dependent on this fragile foundation. However, consider the significance of the USNPC in context. For the ARS and American agriculture, the collection makes possible a multifaceted research program contributing to our understanding of the diversity and significance of helminth and protozoan parasites and pathogens in ruminants, equines, and wildlife species. For the United States and North America, the collection and other dispersed museum and institutional resources make parasitological research possible.

Concurrent with diminishing resources for collections is the realization that the value of systematics has been overlooked especially in parasitology. Except perhaps in the context of a limited number of National Science Foundation (NSF) Partnerships for Enhancing Expertise in Taxonomy (PEET), projects that support systematics of the Eucestoda, Nematoda, and Apicomplexa, the number of systematists continues to decrease, making training opportunities rare in North America. Thus, the current trend for inclusion of parasites in projects supported by the Division of Environmental Biology through the Biotic Survey and Inventory Program (BS\&I) of the NSF is highly laudable and is indicative of recognition of parasites and parasitism as components of biocomplexity. Despite this recognition by a broader community, neither the BS\&I nor PEET have been drivers of the cultural change that is clearly necessary in the academic sector. As has been noted by Brooks and Hoberg (2001), saving biodiversity and promoting human socio-economic development is a complex problem requiring networks of people and of research programs. Networks require common language and discourse, as well as collaborative development of theory and research capacity. Fully trained modern systematists are the masters of a language powerful enough to facilitate such necessary discourse.

The health of parasitology is inextricably linked to the health and continuity of systematics and its museum collections. As a community, this emphasizes the urgent need for scientists, societies, and institutions to seek mandates for support of basic systematics, for support of museums, and for initiation of processes that will strengthen and build new avenues for the dissemination and application of information online. Concurrently systematists must embrace a transition from being collectors of specimens to functioning as curators of information, particularly information that is broadly relevant to science and society (Brooks and Hoberg, 2000). Parasite taxonomists must strive for a cultural change and recognize the need to present a stronger case to those who use systematics information but do not understand the intrinsic significance of the information on which they are dependent. A duality is evident-at once a challenge for all of parasitology to participate and at once an opportunity to build a cooperative and synergistic framework for promoting contributions to a larger infrastructure for global biodiversity. Parasitology can reestablish and maintain relevancy in a dynamic world.

\section{ACKNOWLEDGMENTS}

My career in systematics has been the consequence of working with powerful and insightful mentors, particularly Robert Rausch and Gerald Schmidt, whose seminal studies provided a remarkable view of the world. Our current major collections were developed and expanded through the vision of J. Ralph Lichtenfels at the U.S. National Parasite Collection and Mary Hanson Pritchard at the Harold W. Manter Laboratory. Ideas presented in this paper were articulated over the past several years during collaborations with Daniel Brooks at the University of Toronto and Douglas Causey at the Museum of Comparative Zoology, Harvard University. I also appreciate the insights gained from conversations with Gerardo Pérez-Ponce de León and Virginia León-Regagnon at the Instituto de Helmintologia, Universidad Nacional Autonoma de Mexico, Mexico City. Additionally, my colleagues at the USNPC, Benjamin Rosenthal and J. Ralph Lichtenfels, and Kurt Galbreath contributed to the development of this paper.

\section{LITERATURE CITED}

Barta, J. R. 1989. Phylogenetic analysis of the Class Sporozoea (Phylum Apicomplexa Levine, 1970): evidence for the independent evolution of heteroxenous life cycles. Journal of Parasitology 75: 195-206. 
Bisby, F. A. 2000. The quiet revolution: biodiversity informatics and the Internet. Science 289:23092312 .

Blackmore, S. 1996. Knowing the earth's biodiversity: challenges for the infrastructure of systematic biology. Science 274:63-64.

Brooks, D. R. 1977. Evolutionary history of some plagiorchoid trematodes of anurans. Systematic Zoology 26:277-289.

Brooks, D. R., and E. P. Hoberg. 2000. Triage for the biosphere: the need and rationale for taxonomic inventories and phylogenetic studies of parasites. Comparative Parasitology 67:1-25.

Brooks, D. R., and E. P. Hoberg. 2001. Parasite systematics in the 21st century: opportunities and obstacles. Trends in Parasitology 17:273-275.

Brooks, D. R., and D. A. McLennan. 1993. Parascript: Parasites and the Language of Evolution. Smithsonian Insitution Press, Washington, D.C. 429 p.

Brooks, D. R., R. T. O'Grady, and D. R. Glenn. 1985. The phylogeny of the cercomeria Brooks, 1982 (Platyhelminthes). Proceedings of the Helminthological Society of Washington 52:1-20.

Caira, J. N., K. Jensen, and C. J. Healy. 1999. On the phylogenetic relationships among tetraphyllidean, lecanicephalidean, and diphyllidean tapeworm genera. Systematic Parasitology 42:77-151.

Caira, J. N., K. Jensen, and C. J. Healy. 2001. Interrelationships among tetraphyllidean and lecanicephalidean cestodes. Pages 135-158 in D. T. J. Littlewood and R. A. Bray, eds. Interrelationships of the Platyhelminthes. The Systematics Association Special Volume Series 60. Taylor and Francis, London, U.K.

Carreno, R. A., B. E. Schnitzler, A. C. Jeffries, A. M. Tenter, A. M. Johnson, and J. R. Barta. 1998. Phylogenetic analysis of Coccidia based on 18 s r DNA sequence comparison indicates that Isospora is most closely related to Toxoplasma and Neospora. Journal of Eukaryote Microbiology 45:184-188.

Creswell, I. D. 2000. The global taxonomy initiative, quo vadis? Biology International 38:12-16.

Edwards, J. L., M. A. Lane, and E. S. Nielsen. 2000. Interoperability of biodiversity databases: biodiversity information on every desktop. Science 289:2312-2314.

Gouÿ de Bellocq, J., H. Ferté, J. Depaquit, J. L. Justine, A. Tillier, and M. C. Durette-Desset. 2001. Phylogeny of the Trichostrongylina (Nematoda) inferred from 28 s rDNA sequences. Molecular Phylogenetics and Evolution 19:430-442.

Hoagland, K. E. 1996. The taxonomic impediment and the convention on Biodiversity. Association of Systematics Collections Newsletter 24:61-62, 66-67.

Hoberg, E. P. 1997a. Phylogeny and historical reconstruction: host-parasite systems as keystones in biogeography and ecology. Pages 243-261 in M. L. Reaka-Kudla, D. E. Wilson, and E. O. Wilson, eds. Biodiversity II: Understanding and Protecting Our Biological Resources. Joseph Henry Press, Washington, D.C.
Hoberg, E. P. 1997b. Parasite biodiversity and emerging pathogens: a role for systematics in limiting impacts on genetic resources. Pages 71-83 in K. E. Hoagland and A. Y. Rossmann, eds. Global Genetic Resources: Access Ownership and Intellectual Property Rights. Association of Systematics Collections, Washington, D.C.

Hoberg, E. P., N. L. Alkire, A. de Queiroz, and A. Jones. 2001. Out of Africa: origins of the Taenia tapeworms in humans. Proceedings of the Royal Society London Series B 268:781-787.

Hoberg, E. P., S. L. Gardner, and R. A. Campbell. 1997. Paradigm shifts and tapeworm systematics. Parasitology Today 13:161-162.

Hoberg, E. P., A. A. Kocan, and L. G. Rickard. 2001. Gastrointestinal strongyles in wild ruminants. Pages 193-227 in W. Samuel, M. Pybus, and A. A. Kocan, eds. Parasitic Diseases of Wild Mammals. Iowa State University Press, Ames, Iowa.

Hoberg, E. P., and J. R. Lichtenfels. 1994. Phylogenetic systematic analysis of the trichostrongylidae (Nematoda) with an initial analysis of coevolution and biogeography. Journal of Parasitology 80:976-996.

Hoberg, E. P., J. Mariaux, and D. F. Brooks. 2001. Phylogeny among the orders of the Eucestoda (Cercomeromorphae): integrating morphology, molecules and total evidence. Pages 112-126 in D. T. J. Littlewood and R. A. Bray, eds. Interrelationships of the Platyhelminthes. The Systematics Association Special Volume Series 60. Taylor and Francis, London, U.K.

Hoberg, E. P., J. Mariaux, J. L. Justine, D. R. Brooks, and P. J. Weekes. 1997. Phylogeny of the orders of the Eucestoda (Cercomeromorphae) based on comparative morphology: historical perspectives and a new working hypothesis. Journal of Parasitology 83:1128-1147.

Hoberg, E. P., K. Monsen, S. J. Kutz, and M. Blouin. 1999. Structure, biodiversity and historical biogeography of nematode faunas in Holarctic ruminants: morphological and molecular diagnoses for Teladorsagia boreoarcticus n. sp. (Nematoda: Ostertagiinae), a dimorphic cryptic species in muskoxen (Ovibos moschatus). Journal of Parasitology 85:910-934.

Just, J. 1998. Biodiversity: the scene in Australia and the role of the Australian Biological Resources Study. International Journal for Parasitology 28: 881-885.

Justine, J. L. 1998. Spermatozoa as phylogenetic characters for the Eucestoda. Journal of Parasitology 84:385-408.

Lichtenfels, J. R. 1994. Toward a national plan for parasite collections. Journal of Parasitology 80: 833-840.

Lichtenfels, J. R., E. P. Hoberg, and P. A. Pilitt. 1998. US National Parasite Collection. Pages 1-7 in J. R. Lichtenfels, J. H. Kirkbride, and D. J. Chitwood, eds. Systematics Collections of the Agricultural Research Service. U.S. Department of Agriculture, Miscellaneous Publication No. 1343.

Lichtenfels, J. R., P. A. Pilitt, and E. P. Hoberg. 
1992. The U.S. National Parasite Collection-a century of service. Journal of Parasitology 78 : 924-929.

Littlewood, D. T. J., and R. A. Bray (eds.). 2001. Interrelationships of the Platyhelminthes. The Systematics Association Special Volume Series 60. Taylor and Francis, London, U.K. 356 p.

Mariaux, J. 1998. A molecular phylogeny of the Eucestoda. Journal of Parasitology 84:114-125.

Morell, V. 1996. Web-crawling up the tree of life. Science 273:568-570.

Nadler, S. A., and D. S. S. Hudspeth. 2000. Phylogeny of the Ascaridoidea (Nemaoda: Ascaridida) based on three genes and morphology: hypotheses of structural and sequence evolution. Journal of Parasitology 86:380-393.

Olson, P. D., and J. N. Caira. 1999. Evolution of the major lineages of tapeworms (Platyhelminthes: Cestoidea) inferred from 18s ribosomal DNA and elongation factor $1 \propto$. Journal of Parasitology 85 : 1134-1159.

Olson, P. D., D. T. J. Littlewood, R. A. Bay, and J. Mariaux. 2001. Interrelationships and evolution of the tapeworms (Platyhelminthes: Cestoda). Molecular Phylogenetics and Evolution 19:443-467.

PCAST (President's Council of Advisors on Science and Technology). 1998. Teaming with life: Investing in science to understand and use America's living capital. PCAST Panel on Biodiversity and Ecosystems, Washington, D.C. 86 pp.

Pennisi, E. 2000. Taxonomic revival. Science 289: 2306-2308.

Pérez-Ponce de León, G., and L. Garcia-Prieto. 2001a. Diversidad de helmintos parásitos de vertebrados silvestris de México. Biodiversitas 6:711.

Pérez-Ponce de León, G., and L. Garcia-Prieto. 2001b. Los parásitos en el contexto de la biodiversidad y la conservación. Biodiversitas 6:11-15.

Pérez-Ponce de León, G., L. Garcia-Prieto., V. León-Regagnon, and A. Choudhury. 2000. Helminth communities of native and introduced fishes in Lake Pátzcuaro, Michoacán, Mexico. Journal of Fisheries Biology 57:303-325.

SA 2000 (Systematics Agenda 2000). 1994. Systematics Agenda 2000: Charting the biosphere. Technical Report. American Museum of Natural History, New York. 34 pp.

Wilson, E. O. 2000. A global biodiversity map. Science 289:2279.

Zimmer, C. 2000. Parasite Rex. Free Press, Simon and Schuster, New York. 298 p. 